\title{
The efficacy of diclazuril (liquid formulation) in the prevention and control of coccidiosis in broiler chicken.
}

\author{
M. M. Amer ${ }^{1}$, Wafaa A. Abd el-Ghany ${ }^{1}$, Aziza M. Amer ${ }^{2}$, A. E. A. Hanafei ${ }^{3}$, \\ G. A. Zohair ${ }^{4}$ \\ ${ }^{1}$ Poultry. Diseases. Department., ${ }^{2}$ Pharmacology. Department Faculty. of Veterinary. Medicine. Cairo \\ University. ${ }^{3}$ El-Wadi Poultry. Co. Giza and ${ }^{4}$ Faculty. of Agriculture., Departement. of animal production., \\ Sanaa University., Yemen.
}

This study was carried out to evaluate the efficacy of water soluble formulation of diclazuril (1\%) in the prevention and control of mixed Eimeria infection in two experimental (semifield) trials and testing efficacy of this medicament in controlling of natural field case of mixed Eimeria infection. The experimental (semifield) trials carried out each on 150-day-old broiler chicks, as they were divided into 3 equal separate subgroups. Infected groups were orally received $1 \mathrm{ml}$ of an inoculum containing 50.000 sporulated oocysts of Eimeria tenella, E. acervulina and E. necatrix/ chick at 14 days of age. Diclazuril (1\%) liquid at dose of $1 \mathrm{ml} / 4$ liter of drinking water for 2 successive days just after appearance of bloody dropping (at the $5^{\text {th }}$ day post infection). Birds were given prophylactic diclazuril dose $\left(1 \mathrm{ml} / 8\right.$ liter) at the $7^{\text {th }}$ day before the experimental inoculation. In both trials were oocyst count (shedding) in the dropping, dropping score, lesion score, body weight gain \% and mortality rate were evaluated. Groups treated with diclazuril either in the prophylactic and curative studies gave significant and satisfactory improvement in the assessment criteria when compared with infected non medicated groups.

A field trial was conducted 2 commercial broiler chicken farm consisted of 2 flocks aged 33 days; 6000 birds each. Flock (1) was kept as control positive infected non medicated group, whereas flock (2) was medicated with diclazuril (1\%) at dose of $1 \mathrm{ml} / 4$ liter of the drinking water for 2 successive days. The results revealed more reduction in total oocyst count, lesion score and the mortality rate in the medicated than the infected non-treated group. The results proved that diclazuril (1\%) liquid is effective in prevention and control of both experimental and field infection field circulating Eimeria species still sensitive to the drug.

Coccidiosis is a common disease complex in poultry caused by infection by members of the genus Eimeria. Economic losses are incurred not only as a result of mortality and poor performance of surviving birds, but also as a result of the cost of routine prophylactic and therapeutic medication (Williams, 1999).

There are several species of Eimeria that parasitize chickens (Shirley, 1986) and the pathogenic effects of virulent field strains vary, according to Eimeria species, from a mild to severe haemorrhagic enteritis and death (Williams, 1998).

As the world's poultry production continues to grow, so do concerns about the control of coccidiosis, which remains one of the most commonly reported disease of chickens (Biggs, 1982; Xie et al., 2001). Moreover, although prophylactic administration of conventional anticoccdial drugs in the feed, outbreaks of coccidiosis still occurred in the field (Chapman, 1987).

Evaluation of any anticoccidial drug is based upon estimation of bird's performance criteria such as growth rate and feed conversion, and parasitological criteria including oocyst shedding and the presence of pathognomonic intestinal lesions (Reid et al., 1969; Champan, 1998).

Anticoccidial compounds should be highly effective against all developmental stages of Eimeria species, don't affect on the host immune response as well as have no residues in the tissues. In this respect, diclazuril is one of a series of benzenacetonitrile derivatives. The prophylactic anticoccidial efficacy of diclazuril in feed was extensively studied in chickens (Chapman, 1989; Vanparijs et al., 1989b,e,f; McDougald et al., 1990a,b; Vieira and Clemente, 1995; Chapman, 1998; Conway et al., 2001a,b and 2002a,b ; Kiaei et al., 2001; Awaad 
et al., 2003 ; Meireles et al., 2003), turkeys (Vanparijs et al., 1989c; McDougald et al., 1991 ; Chapman et al., 2004), pigeons (Vercruysse, 1990), pheasants (Vanparijs et al., 1990), partridges (Vanparijs et al., 1991) and rabbits (Vanparijs et al., 1989a,d) and the drug proved it's efficacy in the prevention of coccidial infection without development of drug resistance.

New formulations of water soluble diclazuril for administration in the drinking water were introduced recently in many parts of the world, and few studies were conducted to study its efficacy in the prevention and control of chicken's coccidiosis (Jiang-ZhongQi, 1999; Mukiibi-Muka et al., 2001; El-Banna et al., 2005 ; El-Dakhly et al., 2006). This investigation was designed to evaluate the efficacy of using water soluble formulation of diclazuril $(1 \%)$ in the prevention and control of mixed Eimeria species infections in broiler chickens as a experimental (semifield) trial, also testing the efficacy of this medicament in the control of naturally infected broiler chickens with mixed Eimeria species as a field trial.

\section{Materials and methods}

Chickens.

Experimental (Semi field) trial. Three hundreds, day-old (Hubbard breed) broiler chicks obtained from commercial poultry company were reared on cleaned and disinfected wire floor cages and given feed and water ad libidum without any additives or coccidiostates. These chicks were given Hitchner B1 and La Sota vaccines at 5 and 19 days of age, respectively for Newcastle disease vaccination and also given IBD $228 \mathrm{E}$ vaccine at the 12 days of age for infectious bursal disease vaccination; all vaccines were used via eye drop method.

Field trial. A commercial Hubbard breed broiler chicken farm consisted of two flocks of 6000 birds each, aged 33 days and reared on deep litter system were tested in this trial. These birds were suffered severe intestinal and caecal coccidiosis.

The used anticoccidial drug. Diclazuril water soluble formulation (A synthetic molecule belongs to the benzeneacetonitrates) as $1 \%$ in liquid was obtained from Jordan Vet. and Agr. Med. Ind. Co., Jovet. Batch No. 050508. In experimental (semifield) trial, diclazuril was administrated in a prophylactic dose of $1 \mathrm{ml} / 8$ liter of the drinking water at the 7 th day before the experimental infection, while the therapeutic dose of ( $1 \mathrm{ml} / 4$ liter) was used for 2 successive days once the blood was observed in the dropping [at the 5th day post infection (PI)].

In the field trial, diclazuril was administrated in a dose of $1 \mathrm{ml} / 4$ liter for 2 successive days after appearance of signs and mortalities.

Preparation of sporulated oocysts. Mixed Eimeria species non-sporulated oocysts containing E. tenella, E. acervulina and E. necatrix in approximate ratio of 1:2:1 was obtained from Prof. Dr. M. Kutkat, National Research Center, Egypt. The non sporulated oocysts were emulsified in $2.5 \%$ potassium dichromate solution, then filtrated and the filtrate was left for sedimentation. The sediment was washed several times with distilled water. Lastly, the washed oocysts were kept in $2.5 \%$ potassium dichromate solution at room temperature for sporulation. The sporulated oocyst ounte $/ \mathrm{ml}$ done using Mc-Master technique according to Maff (1977); Soulsby (1978). Different Sporulated oocysts species used for experimental infection or field diagnosis identified according to their size (measuring 100 oocysts) as described by Soulsby (1978).

Experimental infection. Each bird of the infected and medicated groups in the experimental (semifield) trial was intracropa inoculated with $1 \mathrm{ml}$ solution containing 50.000 mixed species of E. tenella, E. acervulina and E. necatrix sporulated oocysts on the $14^{\text {th }}$ day of age.

\section{Evaluation of the drug efficacy.}

Total oocyst count (shedding). The dropping of birds in the semifield (experimental) and field trial were collected daily from the $5^{\text {th }}$ (first appearance of blood) till the $7^{\text {th }}$ day post infection (PI) for testing drug efficacy, while the dropping were collected during 2 days before treatment and 7 days post treatment to test the drug curative efficacy. The mean number of non sporulated oocysts / gram of dropping for each group were counted and calculated using McMaster technique as described by Soulsby (1978).

Dropping score. In the (the dropping of each group in the preventive study were collected daily from the $5^{\text {th }}$ to the $7^{\text {th }}$ day (PI), while they were collected during 2 days before and 7 days post treatment in the semi field and field one. The dropping score was graded (1-4) according to the consistency of the dropping and the presence of mucus/ or blood (Johnson and Reid, 1970; Ramadan et al., 1997).

Lesion scoring . Dead and sacrificed birds were 
subjected for macroscopical examination of the intestine and caeci. The lesions were scored on a scale of 0 to 5 according to the severity of the lesions in the small intestine and the caeci (Johnson and Reid, 1970, Conway, 1979; Conway and Mackenzie, 1991). A score (0) denoted no lesions whereas (5) denoted severe lesions.

The body weight gain. The mean body weight gain at the end of observation period (7 days PI) in the experimental was calculated.

The mortality rate. The number of dead birds in both semi-field and field trials were recorded daily.

\section{Experimental design.}

Semifield (experimental) trial. Out of 300 , day old chicks, the first group containing 150 birds was divided into three equal separate subgroups (A1, B1 and C1), each consisted of 50 birds. Group (A1) was kept as control positive infected non medicated group, while group (B1) was kept as control negative non infected non medicated group. Group (C1) was medicated with diclazuril $1 \%$ (water soluble) in a prophylactic dose of 1 $\mathrm{ml} / 8$ liter of the drinking water at the 7 th day before the experimental infection. Both of group (A1) and (C1) were orally infected with $1 \mathrm{ml}$ solution containing 50.000 mixed species of sporulated E. tenella, E. acervulina and E. necatrix oocysts at 14 days of life. The rest of 150 birds in the second group were equally divided into 3 equal subgroups (A2, B2 and C2), 50 birds each. Group (A2) was kept as control positive infected non medicated group, whereas group (B2) was considered as control negative non infected non medicated group. Groups (A2) and $(\mathrm{C} 2)$ were experimentally infected per os with $1 \mathrm{ml}$ solution containing 50.000 mixed species of sporulated E.tenella, E. acervulina and E. necatrix oocysts at 14 days of life. Group (C2) was medicated with diclazuril $1 \%$ (water soluble) in a curative dose of $1 \mathrm{ml} / 4$ liter of the drinking water at the 5th day (PI), just after detection of blood in the dropping. The drug was given for 2 successive days.

The dropping of birds in the prophylactic study were daily collected from the 5th till the 7th day (PI), while the dropping were collected during 2 days before and 7 days post treatment for oocyst count (shedding) and mean dropping score. Dead and sacrificed birds from each group were macroscopically examined and the mean gross lesions of the intestine and caeci were recorded. The mean body weight and the mortality rate at the end of observation period were calculated.
Once a field infection was diagnosed in the two flocks (1 and 2), birds of flock (1) were considered as infected non medicated group, whereas birds of flock (2) were medicated with diclazuril $1 \%$ water soluble formulation at dose $1 \mathrm{ml} \mathrm{/} 4$ liter of the drinking water for 2 successive days.

Freshly voided dropping from each group were collected for 2 days before treatment and for 7 days after treatment from 5 floor areas in X manner / meter square for oocyst count (shedding). Dead and sacrificed birds before and after medication were subjected to post mortem examination for detection of the mean lesion score in the intestine and caeci. The number of dead birds was also recorded for determination of mortality rate in each flock.

Statistical analysis. The obtained data were statistically analyzed by using Analysis of Variance (ANOVA) according to Snedecor and Corchran (1980).

\section{Results and Discussion}

Table (1) showed the prophylactic efficacy of water soluble diclazuril (1\%) at dose of $1 \mathrm{ml} /$ 8 liter of the drinking water against experimental infection with mixed Eimeria species at the 7 th day before the in the semifield (experimental) trial. Water soluble diclazuril induced significant $(\mathrm{P} \leq 0.05)$ reduction in the mean oocyst shedding, dropping score, lesion score and mortality rate when compared with infected non medicated control positive group. Moreover, the drug induced significant $(\mathrm{P} \leq 0.05)$ improvement in the mean body weight gain at the end of observation period in comparison with infected non medicated group. Efficacy of diclazuril as a feed additive in prevention and control of coccidiosis had been studied and proved to be highly effective (Chapman, 1989; Awaad et al., 2003; Meireles et al., 2003).

Effecacy of Diclazuril administration in drinking water was also proved by El-Banna et al., (2005) who investigated that diclazuril in water or feed were of similar efficacy in elimination of experimental infection with $E$. tenella, E. acervulina, E. necatrix, E. maxima and E. Brunetti as shown by increasing body weight gain and survival rate and reduction in faecal shedding, dropping score and lesion score. Furthermore, the results of using diclazuril (1\%) water soluble solution as $1 \mathrm{ml} / 4$ liter of the drinking water for 2 successive days just after appearance of blood in the dropping (5th day PI) 
Table (1): The prophylactic efficacy of diclazuril (water soluble formulation) in experimentally infected broiler chickens with mixed Eimeria species (semifield trial).

\begin{tabular}{|c|c|c|c|c|c|c|c|}
\hline $\begin{array}{l}0 \\
0 \\
0 \\
\vdots \\
0 \\
0\end{array}$ & 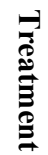 & 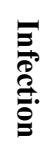 & $\begin{array}{c}\text { Total No. of } \\
\text { oocysts/gm } \\
\text { dropping x } 10^{3}\end{array}$ & $\begin{array}{c}\text { Mean } \\
\text { dropping } \\
\text { score }\end{array}$ & $\begin{array}{l}\text { Mean lesion } \\
\text { score }\end{array}$ & $\begin{array}{l}\text { Mortality } \\
\text { rate }\end{array}$ & $\begin{array}{l}\text { Body weight } \\
\text { gain } \%\end{array}$ \\
\hline$\overline{\mathrm{A} 1}$ & - & + & $46.9 \pm 2.1^{\mathrm{a}}$ & $4.8 \pm 0.91^{\mathrm{a}}$ & $3.1 \pm 0.79^{\mathrm{a}}$ & $(35 / 50) 70$ & $33.25 \pm 4.52^{\mathrm{c}}$ \\
\hline B1 & - & _- & $0.0 \pm 0.0^{\mathrm{c}}$ & $1.0 \pm 0.0^{\mathrm{b}}$ & $0.0 \pm 0.0^{\mathrm{b}}$ & $(0 / 50) \quad 0$ & $48.9 \pm 1.04^{\mathrm{a}}$ \\
\hline $\mathrm{C} 1$ & + & $\overline{+}$ & $3.45 \pm 1.02^{\mathrm{b}}$ & $1.21 \pm 0.1^{\mathrm{b}}$ & $1.02 \pm 0.03^{\mathrm{b}}$ & $(2 / 50) \quad 4$ & $44.01 \pm 1.06^{\mathrm{b}}$ \\
\hline
\end{tabular}

Values within a column with no common superscript are significantly different $(\mathrm{P} \leq 0.05)$.

Table (2): The curative efficacy of diclazuril (water formulation) in experimentally infected broiler chickens with mixed Eimeria species (semifield trial).

\begin{tabular}{|c|c|c|c|c|c|c|c|c|}
\hline \multirow{2}{*}{$\begin{array}{l}0 \\
0 \\
0 \\
0 \\
\vdots \\
0 \\
0\end{array}$} & \multirow{2}{*}{ 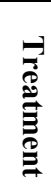 } & \multirow{2}{*}{ 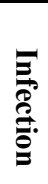 } & \multicolumn{2}{|c|}{$\begin{array}{l}\text { Total No. of oocysts/gm } \\
\text { dropping } \times 10^{3}\end{array}$} & \multirow{2}{*}{$\begin{array}{c}\text { Mean } \\
\text { dropping } \\
\text { score }\end{array}$} & \multirow{2}{*}{$\begin{array}{l}\text { Mean } \\
\text { Lesion } \\
\text { score }\end{array}$} & \multirow{2}{*}{$\begin{array}{l}\text { Mortality } \\
\text { rate }\end{array}$} & \multirow{2}{*}{$\begin{array}{c}\text { Body } \\
\text { weight } \\
\text { gain } \%\end{array}$} \\
\hline & & & $2 \mathrm{DPT}^{*}$ & $7 \mathrm{DPT} *$ & & & & \\
\hline A2 & - & + & $8.9 \pm 0.69^{\mathrm{a}}$ & $55.03 \pm 4.02^{\mathrm{a}}$ & $4.6 \pm 0.3^{\mathrm{a}}$ & $3.7 \pm 0.89^{\mathrm{a}}$ & $(38 / 50) 76$ & $31.3 \pm 2.13^{b}$ \\
\hline B2 & - & - & $0.0 \pm 0.0^{\mathrm{b}}$ & $0.0 \pm 0.0^{\mathrm{c}}$ & $1.0 \pm 0.0^{\mathrm{b}}$ & $0.0 \pm 0.0^{\mathrm{c}}$ & $(0 / 50) \quad 0$ & $42.04 \pm 1.05^{\mathrm{a}}$ \\
\hline $\mathrm{C} 2$ & + & + & $7.81 \pm 0.87^{\mathrm{a}}$ & $1.95 \pm 0.11^{\mathrm{b}}$ & $1.5 \pm 0.2^{b}$ & $1.79 \pm 0.95^{\mathrm{b}}$ & $(6 / 50) \quad 12$ & $40.99 \pm 1.08^{\mathrm{a}}$ \\
\hline
\end{tabular}

* DBT: Days before treatment

Values within a column with no common superscript are significantly different $(\mathrm{P} \leq 0.05)$.

in experimentally infected broiler chickens with mixed Eimeria species were obtained in table (2). The drug was very effective as shown by significant $(\mathrm{P} \leq 0.05)$ decrease in the number of oocyst shedding, dropping and lesion scores as compared with infected non-medicated group. Also, diclazuril had the ability to reduce the mortality rate and prevent the reduction of body weight gain caused by coccidial infection. These results agree with those reported by El-Banna et al., (2005); El-Dakhly et al., (2006) who reported that diclazuril in the drinking water was appropriate for use in prevention and treatment of Eimeria infection in chickens as indicated by decreased oocyst number and lesion score in the treated groups. In addition, Jiang-ZhongQi (1999) demonstrated that usage of diclazuril in concentrations $0.25,0.5$ or $1 \mathrm{mg} /$ liter of drinking water of E. tenella infected chickens, body weight increased, losses due to infection were decreased and index of resistance to the infection increased with increasing rate of diclazuril.. The mode of action of diclazuril was studied by Varheven et al., (1989) and concluded that diclazuril treatment primarily affect particular stages in the sexual development of E. maxima and E. brunetti resulting in complete eradication of infection. Brander et al., (1991) stated that diclazuril breaks down all intracellular developmental stages of asexual and sexual cycles of E. tenella, asexual later shizonts of $E$. acervulina and works against sexual and zygote for E. maxima and gametocytes for E. brunetti. Furthermore, Kwazone and Fabio (1994); El-Banna et al., (2005) ; El-Dakhly et al., (2006) confirmed that diclazuril solution induced marked activity in stopping the cycle of coccidial development inside the medicated birds especially when applied on the day of first blood appearance of bird's drooping.

Results of field study (table 3) proved that two days water medication of diclazuril improved the total oocyst count, the lesion score and the mortality rate than non medicated infected group natural infection with Eimeria species. In this respect, Mukiibi-Muka et al., (2001) found both diclazuril and amprolium water treatment were effective in controlling of natural coccidial infection, but diclazuril was the superior in reduction of oocyst shedding.

Due to diclazurl water solubility, short duration of treatment (2 days), small dosage, rapid anticoccidial action against all intracellular developmental stages of the coccidial infections in all poultry species make diclazuril to be more effective in prevention and control of coccidiosis. 
Table (3): The curative efficacy of diclazuril (water soluble formulation) in naturally infected broiler chickens with mixed Eimeria species (field trial).

\begin{tabular}{|c|c|c|c|c|c|c|}
\hline \multirow{2}{*}{$\begin{array}{l}2 \\
\frac{2}{0} \\
\frac{2}{\lambda} \\
\frac{1}{0} \\
0\end{array}$} & \multirow{2}{*}{ 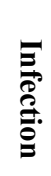 } & \multirow{2}{*}{ 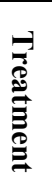 } & \multicolumn{2}{|c|}{$\begin{array}{c}\text { Total No. of oocysts } \\
\text { /gm dropping } \\
\times 10^{3} \\
\end{array}$} & \multirow{2}{*}{$\begin{array}{c}\text { Mean lesion } \\
\text { score }\end{array}$} & \multirow[t]{2}{*}{ Mortality rate } \\
\hline & & & $2 \mathrm{DPT}^{*}$ & 7 DPT* & & \\
\hline 1 & + & - & $9.47 \pm 0.46$ & $60.12 \pm 4.11^{\mathrm{a}}$ & $3.2 \pm 0.33^{\mathrm{a}}$ & $(90 / 6000) 1.5$ \\
\hline 2 & + & - & $8.99 \pm 0.05$ & $0.37 \pm 0.16^{\mathrm{b}}$ & $1.11 \pm 0.74^{\mathrm{b}}$ & 0.3 \\
\hline
\end{tabular}

* DPT: Days before treatment.

Values within a column with no common superscript are significantly different $(\mathrm{P} \leq 0.05)$.

\section{References}

Awaad, M. H.; Manal, A. Afify; Sahar, A. Zouelfakar and Hilali, M. A. (2003): Anticoccidial efficacy of steroidal sapogenins (organic coccidiostate) in broiler chickens (semifield and field trials). Egypt. Vet. Med. Soci. Parasitol. J., 1 (1): 123-136.

Biggs, P. M. (1982): The world of poultry disease. Avian Pathol., 11: 281-300.

Brander, G. C.; Pugh, D. M; Bywater, R. J. and Jenkins, W. L. (1991): Veterinary Applied Pharmacology and Therapeutic, $5^{\text {th }}$ edn. Bailliere Tindall, London, $552 \mathrm{pp}$.

Chapman, H. D. (1987): Control of E. tenella, partly resistant to monensin, by including toltrazuril discontinuously in the drinking water of chickens. J. Comp. Pathol., 97: 21-27. Chapman, H. D. (1989): Eimeria tenella, E. acervulina and E. maxima: Studies on the development of resistance to diclazuril and other anticoccidial drugs in chickens. Parasitol., 99 (2):189-192.

Champan, H. D. (1998): Evaluation of the efficacy of anticoccidial drugs against Eimeria sp. in the fowls. Int. J. Parasitol., 28: 1141-11440.

Chapman, H. D.; Matsler, P. L. and Chapman, M. E. (2004): Control of coccidiosis in turkeys with diclazuril and monensin: effects upon performance and development of immunity to Eimeria species. Avian Dis., 48(3):631-640.

Conway, D. P. (1979): Examination of lesions and lesion scoring: 17-36 in (Poultry coccidiosis Diagnostics and Testing procedures). Pfizer, Int. Inc. NY, USA.

Conway, D. P. and Mackenzie, M. E. (1991): Poultry coccidiosis. Diagnostic and testing procedures. Second Ed. Pfizer.

Conway, D. P.; Mathis, G. F. and Lang, M. (2002a): The use of diclazuril in extended withdrawal anticoccidial programmes: 1. Efficacy against Eimeria spp. In broiler chickens in floor pens. Poultry Sci., 81 (3): 349--352.

Conway, D. P.; Mathis, G. F. and Lang, M. (2002b): The use of diclazuril in extended withdrawal anticoccidial programmes: 2 . Immunity to Eimeria tenella challenge after drug withdrawal. Poultry Sci., 81 (3): 353-355.

Conway, D. P.; Mathis, G. F.; Johnson, J. and Baldwin, C. (2001a): The use of diclazuril in extended withdrawal anticoccidial programmes: 1. Efficacy against Eimeria species in broiler chickens in floor pens. Poultry Sci., 81: 349-352.

Conway, D. P.; Mathis, G. F.; Johnson, J; Schwartz, M. and Baldwin, C. (2001b): Efficacy of diclazuril in comparison with chemical ionophorous anticoccidials against Eimeria spp. in broiler chickens in floor pens. Poultry Sci., 80 (4): 426-430.

El-Banna, H. A.; El-Bahy, M. M.; El-Zorba, H. Y. and ElHady, M. (2005): Anticoccidial efficacy of drinking water soluble diclazuril on experimental and field coccidiosis in broiler chickens. J.Vet..Med.(series A) 52 (6): 287-291.
El-Dakhly, Kh. M.; Azza A. El-Sawah; Shalaby, A, A. and El-Nesr, Kh, A. (2006): The efficacy of Lactobacillus acidophilus and/or diclazuril for inhibition and control of Eimeria tenella infection in balady chicks. Kafr El-Sheikh Vet. Med. J., 4 (1): 1-18.

Jiang-ZhongQi (1999): Study of the efficacy of diclazuril solution in Eimeria tenella inoculated chicks. Zhejiang Nongye Kexue, 1: 44-46.

Johnson, J. and Reid, W. M. (1970): The development of E. tenella in germ free chickens. Fourth International Symposium on Germfree Research. New Orleans, La. April: 16-20.

Kawazone, U. and Fabio, J. D. (1994): Resistance to diclazuril in field isolates of Eimeria sp. obtained from commercial broiler flocks in Brazil. Avian Pathol., 23: 305311.

Kiaei, M. M.; Rahbari, S.; Modirsanei, M.; Rahimi, R. and Aref-Pazhouhi, P. (2001): The effect of Artemisia sieberi and a chemical anticoccidial drug on control of coccidiosis and broiler chicks performance. J. Fac. Vet. Med., Univ. Tehran. 56 (4): 53-57.

Maff, A. (1977): Technical Bulletin no. 18: Manual of veterinary parasitological laboratory techniques. Ministry of Agriculture, Fisheries and Food, London. pp. 58-91.

McDougald, L. R.; Mathis, G. F. and Seibert, B. P. (1990a): Anticoccidial efficacy of diclazuril against recent field isolates of Eimeria from commercial poultry farms. Avian Dis., 34 (4):911-915.

McDougald, L. R.; Mathis, G. F. and Seibert, B. P. (1991): Anticoccidial efficacy of diclazuril against recent field isolates of Eimeria from turkeys farms in the United States. Avian Dis., 35 (4): 863-868.

McDougald, L. R.; Seibert, B. P.; Mathis, G. F. and Quarles, C. L. (1990b): Anticoccidial efficacy of diclazuril in broilers under simulated natural conditions in floor pens. Avian Dis., 34 (4):905-910.

Meireles, M. V.; Kavavata, G. M.; Almeida, S. M.; Hisano, M. and Santos, R. F. (2003): Evaluation of resistance to anticoccidial drugs in field isolates of Eimeria oocysts from broiler farms. Revista Brasileria de Ciencia Veterineria. 10 (2): 72-77.

Mukiibi-Muka, G.; Otim, M. O.; Musisi, G; Lango, J; Galiwango, T. and Olaho-Mukani, W. (2001): Comparative study on the efficacy of diclazuril and amprolium in naturally infected broilers in Uganda. Revue-d'-Elevage-et-deMedecine-Veterinaire-des-Payes Tropicaaux . 54 (1): 33-35.

Ramadan, A.; Abo El-Sooud, K. and El-Bahy, M. M. (1997): Anticoccidial efficacy of toltrazuril and halofuginone against Eimeria tenella infection in broiler chickens in Egypt. Res. Vet. Sci., 62: 175-178.

Reid, W. M.; Brewer, R. N.; Johnson, J.; Taylor, E. M.; Hegde, K. S. and Kowalski, L. M. (1969): Evaluation of 
techniques used in studies on the efficacy of anticoccidial drugs in chickens. American J. Vet. Res., 30: 447-459.

Shirley, M. W. (1986): New methods for the identification of species and strains of Eimeria. In L. R. McDougald, P. L. Long and L. P. Joyner (Eds.), Research in Avian Coccidiosis, Proceedings of he Georgia Coccidiosis Conference 1985 (pp. 13-35). University of Georgia, Athens, GA.

Snedecor, G. W. and Corchran, W. G. (1980): Statistical Methods. Iowa State University Press, Ames, IA.

Soulsby, E. J. L. (1978): Helminthes, Arthropod and Protozoa of domestic animals. $6^{\text {th }}$ ed. Bailliere and Tindall, London.

Vieira, M. and Clemente. (1995): Anticoccidial efficacy of diclazuril in broilers. Veterinaria Tecnica., 5 (4): 36-39.

Vanparijs, O.; Desplenter, L.; Marsboom, R. (1989a): Efficacy of diclazuril in the control of intestinal coccidiosis in rabbits. Vet Parasitol., 34 (3):185-190.

Vanparijs, O.; Desplenter, L.; Marsboom, R. (1989b): Diclazuril, a new broad spectrum anticoccidial drug in chickens: 1. dose titration studies and pilot floor pen trials. Poultry Sci., 68 (4): 489-495.

Vanparijs, O.; Desplenter, L.; Marsboom, R. (1990): Anticoccidial efficacy of diclazuril in pheasants. Vet. Rec., 126 (14):332-333.

Vanparijs, O.; Hermans, L.; Marsboom, R. (1989c): Efficacy of diclazuril against turkey coccidiosis in a floor pen experiment. Avian Dis., 33 (3): 479-481.

Vanparijs, O.; Hermans, L.; Marsboom, Anticoccidial efficacy of diclazuril in partridges. vet. Kec. 129: 339-340.

Vanparijs, O.; Hermans, L.; van der Flaes, L. and
Marsboom, R. (1989d):

Efficacy of diclazuril in the prevention and cure of intestinal and hepatic coccidiosis in rabbits. Vet. Parasitol., 32 (23):109-117.

Vanparijs, O.; Marsboom, R. ; Hermans, L. and van der Flaes, L. (1989e): Diclazuril, a new broad spectrum anticoccidial drug in chickens: 2 . battery trials. Poultry Sci., 68(4):496-500.

Vanparijs, O.; Marsboom, R. ; Hermans, L. and van der Flaes, L. (1989f): Diclazuril, a new broad spectrum anticoccidial for chickens: 3. floor pen trials. Poultry Sci., 69(1): 60-64.

Varheven, A.; Maes, L; Coussement, W.; Vanparijs, O.;Lauwers, F.; Vlaminckx, E. and Marsboom, R. (1989): Ultrastructural evaluation of the effects of diclazuril on the endogenous stages of Eimeria maxima and Eimeria brunetti in experimentally inoculated chickens. Parasitol. Res., 75 (8): 604-610.

Vercruysse, J. (1990): Efficacy of toltrazuril and clazuril against labbeana and Eimeria columbarum in experimental infections with Eimeria racing pigeons. Avian Dis., 34 (1):7379

Williams, R. P. (1998):Epidemiological aspects of the use of live anticoccidial vaccines for chickens. Int. J. Parasitol., 28: 1089-109

Williams, R. P. (1999): A compartmentalized model for the estimation of the cost of coccidiosis to the world's chicken production industry. Int. J. Parasitol., 29: 1209-1229.

Xie, M.; Cai, J.; Li, A. and Peng, X. (2001): Coccidiosis of domestic fowl in China. Proc. of the VIII ${ }^{\text {th }}$ Internal. Coccidiosis Conf., Palm Cove (pp. 153-154). Sydney, Austral

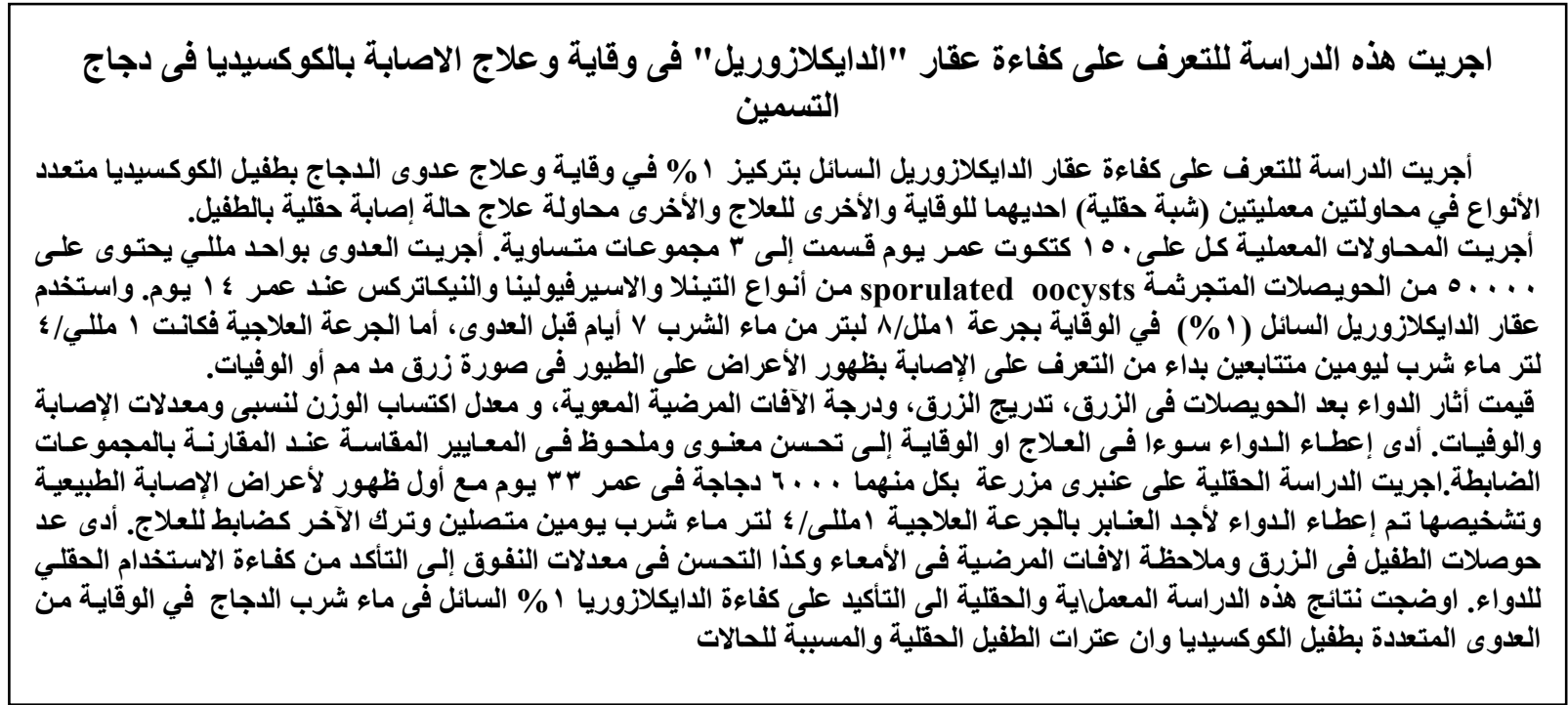



